\title{
Air quality over Portugal: now and in 2050
}

\author{
A. Monteiro, E. Sá, A. Fernandes, C. Gama, S. Sorte, \\ C. Borrego \& M. Lopes \\ CESAM and Department of Environment and Planning, \\ University of Aveiro, Portugal
}

\begin{abstract}
The air quality standards guidelines defined by the World Health Organization, continues to be much more exigent than the actual EU legislation, namely regarding the main critical pollutants over Europe: ozone $\left(\mathrm{O}_{3}\right)$ and particulate matter (PM10 and PM2.5).

This work intends to evaluate the fulfilment of these standards in the present and in the future, including climate change (CC) effects. This study will be focused on the region of Portugal, where each year PM10 concentrations are exceeding the legislated limit values. For that, regional air quality simulations for present and future periods were conducted, with CAMx, to investigate the impacts of CC and anthropogenic emission projections on air quality over Portugal in 2050. The climate and the emission projections for 2050 were derived from the RCP8.5 scenario.

Modelling results indicate serious health impacts due to PM airborne concentrations for both long-term and short-term exposure. The annual averages for both PM10 and PM2.5 exceed the air quality standard (AQS) throughout the country. The PM short-term exposure is already very high for present-day conditions and higher impacts are expected for future scenarios in particular regarding the PM10 values. This is justified by the warmer and dryer conditions and the increase of background concentrations of pollutants in future climate. The results evidence that urgent air quality management strategies need to be designed, considering transboundary cooperation and implementation.
\end{abstract}

Keywords: air quality, WHO guidelines, human health effects, emission projection, climate scenarios. 


\section{Introduction}

Air quality guidelines, published by the World Health Organisation (WHO) for the first time in 1987 [1] based on expert evaluation of current scientific evidence, are intended for worldwide use and have been developed to support actions to achieve air quality that protects public health in different contexts. The last update of WHO guidelines is from 2005 and is "intended to inform policy-makers and to provide appropriate targets for a broad range of policy options for air quality management in different parts of the world" [2]. Nevertheless, countries have defined air quality standards to protect the public health of their citizens which do not necessarily follow the Air Quality Guidelines (AQG) defined by WHO. National standards vary according to the approach adopted for balancing health risks, technological feasibility, economic considerations and various other political and social factors, which in turn depend on, among other things, the level of development and national capability in air quality management.

These AQG are based on up-to-now scientific evidence relating to air pollution and its health consequences. Although this information base has gaps and uncertainties, it offers a strong foundation for the recommended guidelines [1]. Several key findings that have emerged in recent years evidence that both ozone $\left(\mathrm{O}_{3}\right)$ and particulate matter $(\mathrm{PM})$ have associated risks to health at concentrations currently found in many cities in developed countries [1]. Moreover, as research has not identified thresholds below which adverse effects do not occur, it must be stressed that these guideline values cannot fully protect human health. An increasing range of adverse health effects has been linked to air pollution, and at ever-lower concentrations, in particular for particulate matter. The last revision of the WHO AQG for Europe provides new guideline values for these two pollutants $\left(\mathrm{O}_{3}\right.$ and $\left.\mathrm{PM}\right)$. In addition to the guideline values, interim targets are defined for each pollutant, which are proposed as incremental steps for a progressive reduction of air pollution and are intended for use in areas where pollution is high. These targets aim to promote a shift from high air pollutant concentrations, which have acute and serious health consequences, to lower concentrations values. The purpose of this work is to evaluate how these WHO AQG defined for PM are fulfilled over Portugal region, for present and future prospective. These future scenario/projections of air quality should account for changes in both future emissions and climate due to their closely-coupled impacts on air quality [3]. Major pollutants, such as $\mathrm{O}_{3}$ and $\mathrm{PM}$, are sensitive to changes in weather conditions, which can potentially affect wet and dry deposition, chemical production, natural emissions and background concentrations [4]. On the other hand, since changes in emissions of primary air pollutants and the precursors of secondary pollutants will lead to changes in air quality, adequate emission scenarios must also be used [3,5]. Numerical modelling represents an advantageous tool to assess the influence of future climate scenarios on air pollutant concentrations and, consequently, for air quality management [6]. 


\section{Methodology}

There are different approaches to study air quality under future climate based on air quality modelling systems. In terms of emission scenarios, most of the studies conducted so far perform the future-year simulations based on the IPCC (Intergovernmental Panel for Climate Change) scenarios developed in the last years: IPCC IS92 [7]; IPCC SRES scenarios [8-14]; and IPCC RCP (Representative Concentration Pathways) scenarios [15-17]. Additionally, some studies consider the combination of IPCC scenarios and emission control and mitigation policy scenarios to project future air quality. For example, those studies based on the emission scenarios from IIASA (International Institute for applied System Analysis) that consider current legislation emission (CLE) or maximum feasible reduction (MFR) [18, 19].

To evaluate the combined impact of climate change and anthropogenic emissions on air quality, simulated changes in future air quality in Europe were already performed for the 2030 s and 2050 s, under the RCP8.5 scenario [17]. In particular over Portugal, in the scope of the CLICURB project [20], highresolution simulations were performed for Portugal domain, for both (present and future) scenarios using the WRF-CAMx modelling system, already extensively tested over this study region and exhibiting a good behaviour [21-23, 20].

This study intends to use these numerical simulations, performed at high spatial resolution, to evaluate where the WHO standards are exceeded, and comparing the current and future scenarios. The work is structured as follows. Section 2 describes the modelling system and the simulations setup for the current and future periods. The modelling results are discussed in Section 3. The summary and conclusions are given in Section 4.

Emissions of primary air pollutants and precursors were determined for the two simulation periods. For the REF scenario, a top-down methodology was applied to disaggregate the anthropogenic emissions, using the up-to-date Portuguese national emission inventory (INERPA) [24]. For the future emissions, the EmiProRCP model [25] was applied for the year 2050 under the RCP8.5.

The Weather Regional Forecasting (WRF) model was used to downscale global climate simulations, performed by the Earth Systems Model MPI-ESM-LR, forced only by the greenhouse gases concentrations [26]. The meteorological outputs from the meteorological model WRF with MPI-ESM-LR are used as inputs for the chemistry-transport model CAMxv6.0. CAMx is a Eulerian photochemical dispersion model that considers the emission, dispersion, chemical reaction, and removal of pollutants in the troposphere by solving the pollutant continuity equation for each chemical species [27]. This modelling system was already evaluated in several previous studies $[21-23,28]$ and this particular application for the reference scenario was evaluated using the DELTA tool developed in the scope of the FAIRMODE (Forum for Air Quality Modelling) framework [29, 30]. Results point out that the model performs well in simulating concentrations of $\mathrm{NO}_{2}, \mathrm{O}_{3}$ and PM10, presenting a positive behaviour for all parameters in the DELTA tool, in terms of both time and space [20]. 


\section{Results and discussion}

In this section, the air quality modelling results are explored for both scenarios reference corresponding to current situation (REF) and future climate (FUT) - and one of the most critical pollutants regarding the WHO AQG, namely PM (PM10 and PM2.5). A comparative analysis between the two scenarios is performed, followed by a spatial analysis and discussion about the exceedances of the AQG and its associated human health effects.

The range of health effects associated to air pollution is broad, but are predominantly to the respiratory and cardiovascular systems. The risk for various outcomes has been shown to increase with exposure and there is little evidence to suggest a threshold below which no adverse health effects would be anticipated. To assist this process, the AQG and interim target values settled by WHO reflect the concentrations at which increased mortality responses due to PM air pollution are expected based on current scientific findings [2].

Besides the guideline value, three interim targets (IT) are defined for both PM10 and PM2.5 (according to the guidelines defined by WHO [2] for long-term exposure and for short-term). These interim targets can be particularly helpful for countries in gauging progress over time in the difficult process of steadily reducing population exposures to PM. The modelling results obtained for PM10 and PM2.5 annual average, are presented in Figure 1, respectively, for both scenarios. An annual average was taken for the 5-year simulation period for both scenarios (REF and FUT).

In a future scenario, an increase of PM10 and PM2.5 annual mean levels over Portugal is expected, reaching $30 \%$ in the north and more than $40 \%$ in the south of the domain. This increase is however mainly due to the boundary conditions of the MOZART model. The projections of RCP8.5 for 2050 indicate an increase of MOZART concentrations in terms of dust, which could support this increase in PM10 concentrations [20]. The fulfilment of the WHO AQG is compromised over all the territory, already in current scenario, but particularly critical for future conditions. In future it is expected that even the IT-1 target (the higher concentration levels, associated with about a $15 \%$ higher long-term mortality risk relative to the AQG level) will be surpassed in terms of long-term exposure, with serious mortality risk comparing to the AQG level. This future situation is even more critical for PM2.5 for which exceedances to IT-1 are expected over all Portugal. WHO also defined indicators for the short-term exposure related to particulate matter, as seen in WHO [2].

The modelling results were post-processed in order to estimate the number of days with expected exceedance of the daily mean guidelines, for both PM10 and PM2.5 concentrations. Figure 2 shows these results for the reference (REF) and future (FUT) scenarios.

In terms of short-term exposure (daily-mean levels), and in contrary to the longterm results, the situation is more serious regarding PM10 exposure than PM2.5. More than $50 \%$ of the days are expecting to exceed the AQG for PM10 presently and more than $80 \%$ of the days in future scenario. For PM 2.5 this percentage of the days with exceedance is lower (around 20\% in REF and 50\% in FUT). 


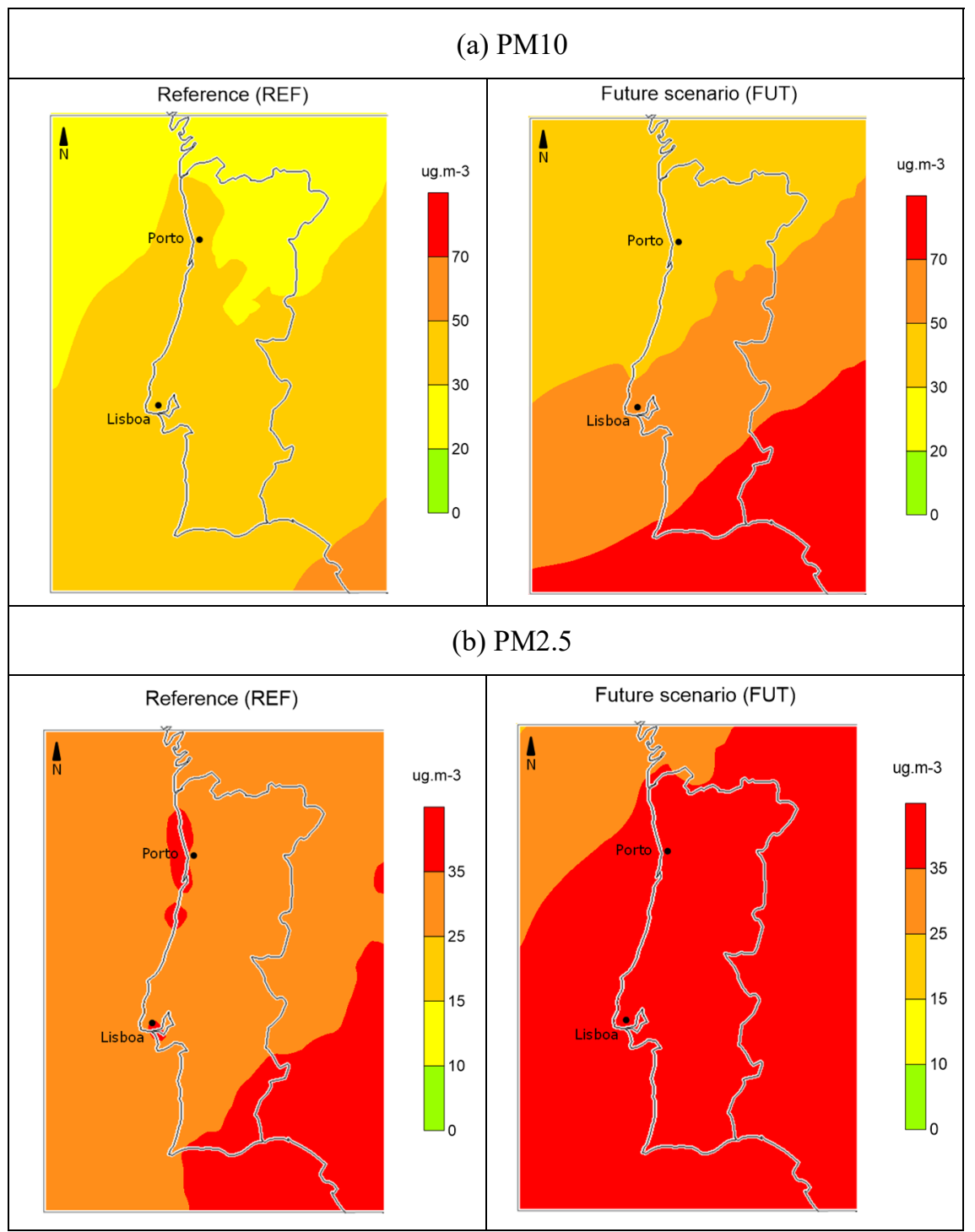

Figure 1: $\quad$ PM10 (a) and PM2.5 (b) annual mean results for the reference (REF) and future (FUT) scenarios. 


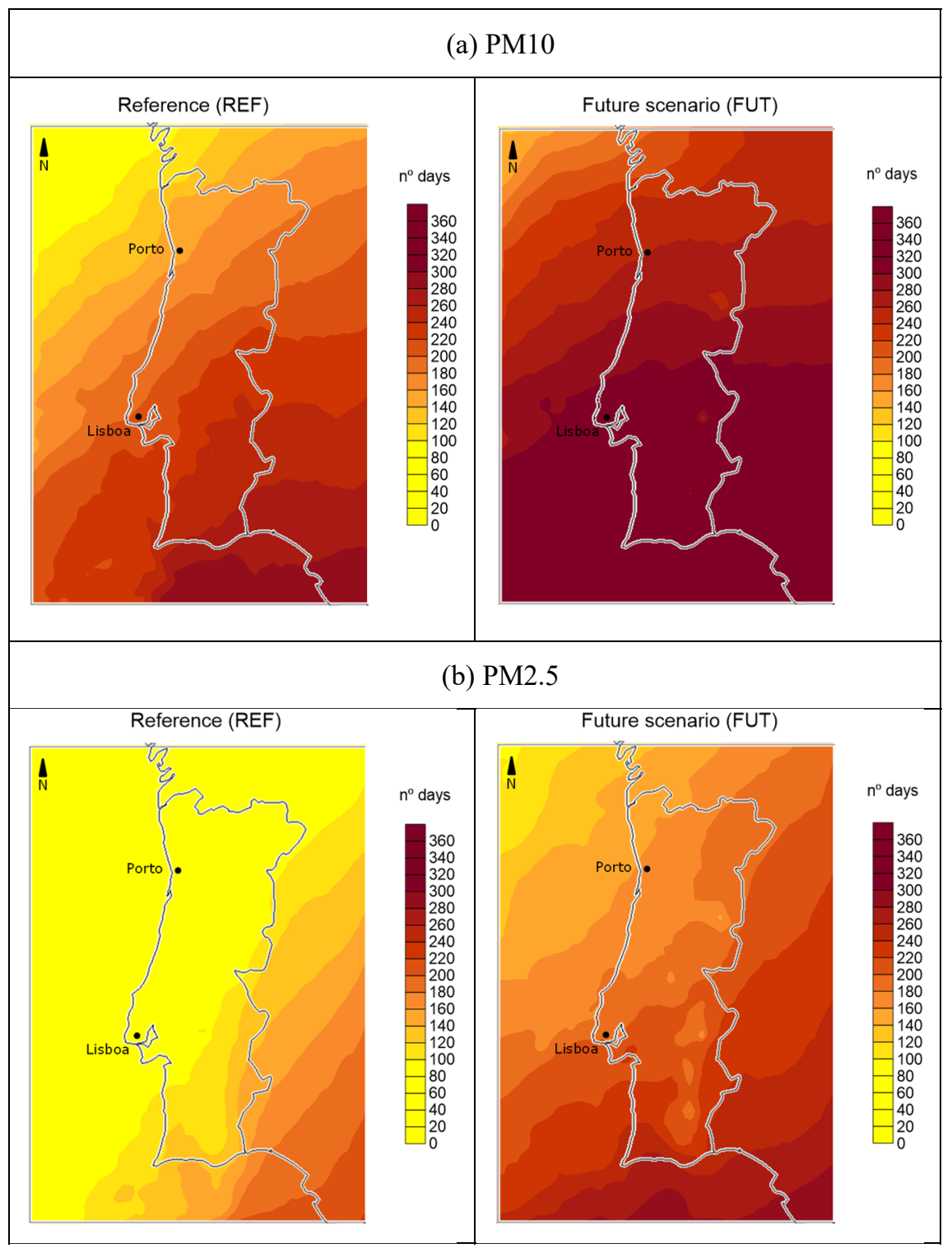

Figure 2: $\quad$ Number of days with exceedance of the daily limit value of (a) PM10 and (b) PM2.5 for reference (REF) and future (FUT) scenarios. 


\section{Summary and conclusions}

The main objective of this study is to investigate how the AQG defined by WHO are fulfilled at present and future conditions over Portugal mainland. To achieve this goal, the CAMx chemistry-transport model, forced by the WRF meteorological outputs, was used to produce the pollutants concentration expected for the present and future (2050) scenarios, considering the impact of climate change.

Modelling results indicate serious problems regarding PM, due to the potential health impact for both long-term and short-term exposure, in particular for future climate scenario. The annual average for both PM10 and PM2.5 exceed the AQG along the all Portugal, surpassing even the IT-1 target in the southern region, in particular for future scenario (which is justified by the RCP8.5 projections of dust increase). The PM short-term exposure is already very high for current conditions with higher impacts for future scenario (more than $50 \%-80 \%$ of the days above the AQG), and in particular regarding the PM10 values. These results show that populations are exposed to pollution levels with risk to health, including cardiopulmonary and lung cancer mortality and premature mortality due to longterm exposure.

These results can be mostly important to support current and future air quality management strategies. The design and implementation of mitigation plans by regional/national authorities and policy-makers have to take into account the current scenario, together with the emission projections and climate change impacts. Only this integrated analysis can promote a successfully progress towards the AQG fulfilment and health risk reduction in all areas.

\section{Acknowledgements}

The authors wish to express thanks for the financial support of FEDER through the COMPETE Programme and the national funds from FCT - Science and Technology Portuguese Foundation for financing the AIRSHIP project (PTDC/AAG-MAA/1581/2014) and the Ph.D. grants of A. Fernandes (SFRH/BD/86307/2012) and C. Gama (SFRH/BD/87468/2012). Thanks are also due, for the financial support to CESAM (UID/AMB/50017), to FCT/MEC through national funds, and the co-funding by the FEDER, within the PT2020 Partnership Agreement and Compete 2020.

\section{References}

[1] WHO (World Health Organization), 1987. Air quality guidelines for Europe. Copenhagen, World Health Organization Regional Office for Europe. WHO Regional Publications, European Series, No. 23.

[2] WHO (World Health Organization), 2006. Air quality guidelines for particulate matter, ozone, nitrogen dioxide and sulfur dioxide: global update 2005, Copenhagen, 484 pages. 
[3] Penrod, A., Zhang, Y., Wang, K., Wu, S.Y., Leung, L.R., 2014. Impacts of future climate and emission changes on U.S. air quality. Atmos. Environ. $89,533-547$.

[4] Jacob, D.J., Winner, D.A., 2009. Effect of climate change on air quality. Atmos. Environ. 43, 51-63.

[5] Zlatev, Z., Moseholm, L., 2008. Impact of climate change on pollution levels in Denmark. Ecol. Model. 217, 305-332.

[6] Carvalho, A., Monteiro, A., Solman, S., Miranda, A.I., Borrego, C., 2010. Climate-driven changes in air quality over Europe by the end of the $21 \mathrm{st}$ century, with special reference to Portugal. Environ. Sci. Policy 13, 445458.

[7] J. Leggett, W.J. Pepper, R.J. Swart, J. Edmonds, L.G. Meira Filho, I. Mintzer, M.X. Wang, and J. Watson. 1992. "Emissions Scenarios for the IPCC: an Update", Climate Change 1992: The Supplementary Report to The IPCC Scientific Assessment, Cambridge University Press, UK, pp. 68-95.

[8] Doherty, R.M., Wild, O., Shindell, D.T. , Zeng, G., MacKenzie, I.A., Collins, W.J., Fiore, A.M., Stevenson, D.S., Dentener, F.J., Schultz, M.G., Hess, P., Derwent, R.G., Keating, T.J., 2013. Impacts of climate change on surface ozone and intercontinental ozone pollution: a multi-model study. J. Geophys. Res. 118, 3744-3763.

[9] Jiang, H., Liao, H., Pye, H.O.T., Wu, S., Mickley, L.J., Seinfeld, J.H., Zhang, X.Y., 2013. Projected effect of 2000-2050 changes in climate and emissions on aerosol levels in China and associated transboundary transport. Atmos. Chem. Phys., 13, 7937-7960.

[10] Manders, A.M.M., van Meijgaard, E., Mues, A.C., Kranenburg, R., van Ulft, L.H., Schaap, M., 2012. The impact of differences in large-scale circulation output from climate models on the regional modeling of ozone and PM. Atmos. Chem.Phys. 12, 9441-9458.

[11] Nolte, C.G., Gilliland, A.B., Hogrefe, C., Mickley, L.J., 2008. Linking global to regional models to assess future climate impacts on surface ozone levels in the United States. J. Geophys. Res. 113, D14307.

[12] Penrod, A., Zhang, Y., Wang, K., Wu, S.Y., Leung, L.R., 2014. Impacts of future climate and emission changes on U.S. air quality. Atmos. Environ. 89, 533-547.

[13] Tagaris, E., Manomaiphiboon, K., Liao, K., Leung, L.R., Woo, J., He, S., Amar, P.,Russell, A.G., 2007. Impacts of global climate change and emissions on regional ozone and fine particulate matter concentrations over the United States. J. Geophys. Res. 112, D14312.

[14] Trail, M., Tsimpidi, A.P., Liu, P., Tsigaridis, K., Rudokas, J., Miller, P., Nenes, A., Hu, Y., Russel, A.G., 2014. Sensitivity of air quality to potential future climate change and emissions in the United States and major cities. Atmos. Environ. 94, 552-563.

[15] Riahi, K., Rao, S., Krey, V., Cho, C., Chirkov, V., Fisher, G., Kindermann, G., Nakicenovic, N., Rafaj, P., 2011. RCP 8.5 - A scenario of comparatively high greenhouse gas emissions. Clim. Change 109, 33-57. 
[16] Gao, Y., Fu, J.S., Drake, J.B., Lamarque, J.F., Liu, Y., 2013. The impact of emission and climate change on ozone in the United States under representative concentration pathways (RCPs). Atmos. Chem. Phys. 13, 9607-9621.

[17] Lacressonnière, G., Peuch, V. H., Vautard, R., Arteta, J., Déqué, M., Joly, M., Josse, B., Marécal, V., Saint-Martin, D., 2014. European air quality in the 2030s and 2050s: Impacts of global and regional emission trends and of climate change. Atmos. Environ. 92, 348-358.

[18] Dentener, F., Stevenson, D., Cofala, J., Mechler, R., Amann, M., Bergamaschi, P., Raes, F., Derwent, R., 2005. The impact of air pollutant and methane emission controls on tropospheric ozone and radiative forcing: CTM calculations for the period 1990-2030. Atmos. Chem. Phys. 5, 17311755.

[19] Stevenson, D.S., Dentener, F.J. and Schultz, M.G., Ellingsen, K., van Noije, T.P.C., Wild, O., Zeng, G., Amann, M., Atherton, C.S., Bell, N., Bergmann, D.J., Bey, I., Butler, T., Cofala, J., Collins, W.J., Derwent, R.G., Doherty, R.M., Drevet, J., Eskes, H.J., Fiore, A.M., Gauss, M., Hauglustaine, D.A., Horowitz, L.W., Isaksen, I.S.A., Krol, M.C., Lamarque, J.-F., Lawrence, M G., Montanaro, V., Müller, J.-F., Pitari, G., Prather, M.J., Pyle, J.A., Rast, S., Rodriguez, J.M., Sanderson, M.G., Savage, N.H., Shindell, D.T., Strahan, S.E., Sudo, K., Szopa, S., 2006. Multimodel ensemble simulations of present-day and near-future tropospheric ozone. J. Geophys. Res., 111, D08301.

[20] Sá, E., Martins, H., Ferreira, J., Marta-Almeida, M., Rocha, A., Carvalho, A., Freitas, S., Borrego, C., 2016. Climate change and pollutant emissions impacts on air quality in 2050 over Portugal. Atmos. Environ. 131, 209224.

[21] Ferreira J., Martins, H., Monteiro, A., Miranda, A. I., Borrego, C., 2006. Air quality modelling application to evaluate effects of $\mathrm{PM}$ air concentrations on urban population exposure. Epidemiol. 17, S252-S253.

[22] Martins, H., Miranda, A., Borrego, C., 2010. Atmospheric modelling under urban land use changes: meteorological and air quality consequences. 31st NATO/SPS International Technical Meeting on Air Pollution Modelling and its Application, 27 Sept - 1 Oct., Torino, Italy.

[23] Martins H., 2012. Urban compaction or dispersion? An air quality modelling study. Atmos. Environ. 54, 60-72.

[24] APA (Portuguese Environmental Agency), 2014. Portuguese informative inventory report 1990-2012. Submitted under the UNECE convention on long-range transboundary air pollution. Agência Portuguesa do Ambiente (Ed.), Amadora, Portugal, March 2014.

[25] Sá, E., Ferreira, J., Carvalho, A., Borrego, C., 2015. Development of current and future pollutant emissions for Portugal. Atmos. Pollut. Res. 6, 849-857.

[26] Brands, S., Herrera, S., Fernandez, J., Gutierrez, J.M., 2013. How well do CMIP5 Earth System Models simulate present climate conditions in Europe and Africa? A performance comparison for the downscaling community. Clim. Dynam. 41, 803-817. 
[27] Morris, R.E., Yarwood, G., Emery, C., Koo., B., 2004. Development and Application of the CAMx Regional One-Atmosphere Model to Treat Ozone, Particulate Matter, Visibility, Air Toxics and Mercury. 97th Annual Conference and Exhibition of the A\&WMA, June 2004, Indianapolis.

[28] Marta-Almeida, M., Teixeira, J.C., Carvalho, M.J., Melo-Gonçalves, P., Rocha, A.M., 2016. High resolution WRF climatic simulations for the Iberian Peninsula: Model validation. Phys Chem. Earth.

[29] Thunis P., Pederzoli A., Pernigotti D., 2012. Performance criteria to evaluate air quality modelling applications. Atmos. Environ. 59, 476-482.

[30] FAIMODE at Joint Research Centre: http://fairmode.jrc.ec.europa.eu 